\title{
Flora da Usina São José, Igarassu, Pernambuco: Ochnaceae e Quinaceae
}

\author{
Flora of Usina São José, Igarassu, Pernambuco: Ochnaceae and Quinaceae
}

\author{
Fernanda Oliveira Silva ${ }^{1,3}$, Ana Raquel de Lima Lourenço ${ }^{1}$, Maria do Céo Rodrigues Pessoa ${ }^{2}$ \\ \& Marccus Vinícius Alves ${ }^{1}$
}

\begin{abstract}
Resumo
Ochnaceae s.s., Quiinaceae e Medusagynaceae são filogeneticamente relacionadas e por vezes consideradas como Ochnaceae s.l., sendo apenas as duas primeiras conhecidas para o Brasil. Ochnaceae s.s. ocorre nas regiões tropicais e subtropicais, enquanto Quiinaceae é exclusivamente neotropical e predominantemente amazônica. No nordeste do Brasil, estão registrados os gêneros Elvasia DC., Luxemburgia A.St.-Hil., Ouratea Aubl., Sauvagesia L. (Ochnaceae s.s.) e Lacunaria Ducke e Quiina Aubl. (Quinaceae). Na Usina São José (USJ), Ochnaceae está representada por Ouratea castaneifolia (DC.) Engl., O. crassa Tiegh., O. hexasperma (A.St.Hil.) Baill. e Sauvagesia erecta L., e Quiinaceae por Q. florida Tul. O trabalho inclui chave de identificação, descrições, comentários gerais sobre distribuição geográfica e habitats, caracteres diagnósticos e ilustrações. Palavras-chave: taxonomia, Mata Atlântica, Ochnaceae, Quiinaceae.
\end{abstract}

\begin{abstract}
Ochnaceae s.s., Quiinaceae and Medusagynaceae are phylogenetically related and sometimes treated as Ochnaceae s.l., but only the first ones are recorded to Brazil. Ochnaceae s.s. occurs in tropical and subtropical while Quiinaceae is exclusively neotropical and predominantly distributed in the Amazon forest. In northeastern Brazil, the recognized genera are Elvasia DC., Luxemburgia A.St.-Hil., Ouratea Aubl., and Sauvagesia L. (Ochnaceae s.s.), and Lacunaria Ducke and Quiina Aubl.(Quinaceae). In the Usina São José is represented by Ouratea castaneifolia (DC.) Engl., O. crassa Tiegh., O. hexasperma (A.St.-Hil.) Baill., and Sauvagesia erecta L. (Ochnaceae s.s.), and Quiina florida Tul. (Quiinaceae). This study includes identification key, descriptions, general comments about the species and habitats, and illustrations.

Key-words: taxonomy, Atlantic rainforest, Ochnaceae, Quiinaceae.
\end{abstract}

\section{Introdução}

Ochnaceae, Quiinaceae e Medusagynaceae, incluindas em Malpighiales, constituem um grupo monofilético com relações ainda controversas (APG III 2009). Alguns autores sugerem que sejam tratadas como Ochnaceae s.l., devido ao bom suporte nas análises filogenéticas e a baixa diferenciação molecular intrafamiliar (Chase et al. 2000; Savolainen et al. 2000; APG 2003). Schneider et al. (2006), no entanto, sugere que Quiinaceae e Ochnaceae s.str. são famílias bem estabelecidas filogeneticamente.

Ochnaceae é composta por 27 gêneros e cerca de 600 espécies, ocorrendo no trópico e subtrópico (Amaral 1991), sendo Ouratea Aubl. e Sauvagesia L. os mais diversos nos Neotrópicos (Sastre 2003b). São, em geral, árvores, arbustos ou raramente ervas com folhas simples e alternas, com estípulas caducas ou persistentes. As flores são bissexuadas, actinomorfas, diclamídeas, com pedicelos articulados. Possuem pétalas amarelas, esbranquiçadas, róseas ou lilases. $\mathrm{O}$ androceu pode ser diplo, iso ou polistêmone, dialistêmone com as anteras poricidas ou rimosas e por vezes com estaminódios. O gineceu é sincárpico, com 2-10-carpelos, sendo o ovário súpero com estilete ginobásico ou terminal. Os frutos são cápsulas em Sauvagesia e monocarpos ou mericarpos indeiscentes e livres em Ouratea (Sastre 2003c). Para o Nordeste do Brasil, são referidas 51 espécies,

\footnotetext{
${ }^{1}$ Universidade Federal do Pernambuco, Centro de Ciências Biológicas, Depto. Botânica, Programa de Pós Graduação em Biologia Vegetal, R. Prof. Nelson Chaves $\mathrm{s} / \mathrm{n}$, Cidade Universitária, 50670-901, Recife, PE, Brasil.

${ }^{2}$ Universidade Federal da Paraíba, Centro de Ciências Exatas e da Natureza, Depto. Sistemática e Ecologia, C.P. 5065, 58051-970, João Pessoa, PB, Brasil.

${ }^{3}$ Autor para correspondencia: oliveirafs.2@gmail.com
} 
pertencentes a quatro gêneros: Elvasia DC. (1 spp.), Luxemburgia A.St.-Hil. (1 spp.), Ouratea Aubl. (36 spp.) e Sauvagesia L. (13 spp.) presentes no Cerrado, Caatinga e Floresta Atlântica (Chacon et al. 2011).

Quiinaceae é exclusivamente neotropical e predominantemente amazônica (Zizka \& Schneider 2004), composta por quatro gêneros e cerca de 50 espécies (Schneider et al. 2002). São comumente árvores de médio porte, com folhas simples ou compostas pinadas, opostas, decussadas ou verticiladas e estípulas interpeciolares caducas ou persistentes e por vezes, vistosas. As flores são bi ou unissexuadas, actinomorfas e diclamídeas. $\mathrm{O}$ androceu é polistêmone com deiscência rimosa. O gineceu é sincárpico ou apocárpico, sendo o ovário súpero e o estilete terminal. Os frutos são bagas (Souza \& Bianchini 2007; Souza \& Lorenzi 2008). Para o Nordeste do Brasil, são citadas Lacunaria crenata (Tul.) A.C. Sm., Quiina cruegeriana Griseb., Q. florida Tul. e Q. glazovii Engl., todas na Floresta Atlântica (Alves-Araújo et al. 2010).

Apesar de incluídas em um mesmo agrupamento filogenético (APG III 2009), Quiinaceae e Ochnaceae diferem entre si pela filotaxia, morfologia floral e tipo de fruto.

Este estudo é parte da série de monografias taxonômicas para o complexo de fragmentos florestais da Usina São José (Alves-Araújo \& Alves 2010; Melo et al. 2010; Pontes et al. 2010, Buril \& Alves 2011; Amorim \& Alves 2011).

\section{Material e Métodos}

A Usina São José (USJ), localiza-se na Zona da Mata pernambucana, litoral norte do estado e abrange parte dos municípios de Igarassu, Abreu e Lima, Araçoiaba, Goiana, Itapissuma e Itaquitinga
(Trindade et al. 2008). Possui uma área total de aproximadamente $280 \mathrm{~km}^{2}$ distribuída em cerca de 110 fragmentos florestais com diferentes dimensões e formas. Para melhor detalhamento da área, consultar Alves-Araújo \& Alves (2010).

As amostras analisadas da USJ compõem aos acervos dos principais herbários do estado de Pernambuco HST, IPA, PEUFR e UFP (siglas de acordo com Thiers 2011) e foram obtidas no período de 2007-2011. As identificações foram realizadas com apoio de bibliografia específica, incluindo consulta as descrições originais e imagens dos tipos disponíveis online. As descrições e ilustrações dos caracteres morfológicos diagnósticos seguem os modelos das monografias previamente publicadas para a área (Alves-Araújo \& Alves 2010; Melo et al., 2010; Pontes et al. 2010; Buril \& Alves 2011; Amorim \& Alves 2011).

\section{Resultados e Discussão}

Na Usina São José (USJ), Ochnaceae está representada por Ouratea castaneifolia (DC.) Engl., Ouratea crassa Tiegh., Ouratea hexasperma (A.St.Hil.) Baill. e Sauvagesia erecta L., e Quiinaceae está representada por apenas uma espécie, Quiina florida Tul. As espécies $O$. crassa e $O$. castaneifolia, até o momento não tinham sido registradas para Floresta Atlântica do Pernambuco, já as demais espécies de Ochnaceae aqui referidas são amplamente distribuídas no Brasil (Chacon et al. 2011). Quiina florida representa uma disjunção entre a Floresta Atlântica e a Amazônia, padrão comum à varias espécies de Quiinaceae (Araújo-Alves et al. 2010. Apenas O. crassa é endêmica do Brasil (Chacon \& Yamamoto 2011).

\section{Chave de identificação para as espécies de Ochnaceae e Quiinaceae da Usina São José}

1. Ervas; estípulas ciliadas; flores alvas, róseas ou lilases 5. Sauvagesia erecta

1'. Árvores; estípulas não ciliadas; flores amarelas

2. Folhas opostas, fruto baga, com estrias longitudinais. 1.Quiina florida

2'. Folhas alternas, fruto esquizocarpo, sem estrias longitudinais

3. Gineceu (6-8) carpelar, sépalas caducas no fruto imaturo

3'. Gineceu 5 carpelar, sépalas persistentes no fruto imaturo

4. Lâmina foliar 23-35 × 7,3-11 cm; anteras 7-8 mm compr. 4. Ouratea hexasperma

4'. Lâmina foliar 8,2-16 × 3,4-6,5 cm; anteras 4-5 mm compr. 3. O. crassa 2. O. castaneifolia

\section{Quiina Aubl.}

Árvores ou arbustos. Estípulas aos pares, não ciliadas, caducas ou persistentes. Folhas com margem ondulada, inteira ou serreada, nervação camptódroma, nervuras secundárias divergindo em arcos da principal. Inflorescência tirsiforme ou racemiforme, axilar. Pétalas obovais, amarelas; estames 12-60, anteras com filetes conspícuos. Baga globosa ou elíptico-oblonga, estriada longitudinalmente; sementes 1-2. 
O gênero compreende cerca de 40 espécies, ocorrendo desde a América Central até o sul do Brasil, com maior diversidade na região Amazônica (Souza \& Bianchini 2007).

1. Quiina florida Tul. Ann. Sci. Nat., Bot. sér. 3, 11:167. 1849 .

Fig. 1a-b

Árvores, ca. $7 \mathrm{~m}$ de alt., androdióicas. Estípulas $6 \mathrm{~mm}$ compr., elípticas. Folhas 18-19 × 5,5-7 cm, opostas, elípticas, cartáceas, ápice agudo, base atenuada, margem ondulada, inteira; pecíolo 1-1,2 cm. Inflorescência 1,5-3,5 cm compr.; botões florais 2-3 mm compr.; pedicelo 1-3 mm compr. Sépalas $3 \times 1,5-2 \mathrm{~mm}$; pétalas $4 \mathrm{~mm}$ diâm.; anteras 0,4 mm compr.; baga 10-11 mm diâm., globosa.

Material examinado: Mata da Piedade, 16.XII.2009, fr., J.A.N. Sousa 590 (UFP).

Material examinado adicional: BRASIL. ALAGOAS: Ibateguara, Coimbra, 25.IX.2002, fr., M. Oliveira 1110 (IPA). Flexeiras, Fazenda Triunfo, 16.VIII.1968, fl., M.T. Monteiro 22706 (IPA).

Ocorre no Cerrado, Floresta Atlântica e principalmente na Floresta Amazônica (Rocha et al. 2011). Na USJ é rara e está representada por poucos indivíduos ocorrendo em áreas melhor preservadas. Segundo Alves-Araújo et al. (2010) diferenciase das demais espécies de Quiina ocorrentes no Nordeste pelas folhas e estípulas glabras (pilosas em $Q$. cruegeriana) e estípulas elípticas a raramente lanceoladas (ovadas em Q. glazovii).

\section{Ouratea Aubl.}

Árvores a arvoretas. Estípulas aos pares, não ciliadas, caducas ou persistentes. Folhas com margem ondulada, serreada a serrilhada no terço superior, nervação camptódroma, nervuras secundárias divergindo em arcos da principal, pecíolo canaliculado. Inflorescência panícula piramidal, terminal. Pétalas flabeliformes, estames-10, anteras sésseis, levemente a transverso-rugulosa, gineceu 5-8-carpelar, carpelo globoso-oblongo, ginóforo presente, estilete ginobásico. Mericarpos drupóides; lisos; semente 1.

Nos Neotrópicos ocorrem aproximadamente 200 espécies (Sastre 2003a), destas 118 são referidas para o Brasil e 36 para a Região Nordeste (Chacon \& Yamamoto 2011)

2. Ouratea castaneifolia (DC.) Engl. in Mart., Fl. bras. 12 (2): 309.1876.

Fig. 1c-d

Arvoretas ou árvores, 3-10 m alt. Estípulas 4-5 mm compr., deltóides. Folhas 8-16 × 3,4-7 cm, elípticas a oblongo-elípticas, cartáceas, ápice acuminado, base cuneada a obtusa, margem levemente ondulada, serreada no terço superior; pecíolo 0,5-1 cm, canaliculado. Inflorescência 10 $18 \mathrm{~cm}$ compr.; botões florais 5-7 × 2,5-4 mm, ápice agudo, base truncada; pedicelo 5-9 mm compr.; sépalas 6-6,5 × 2-3 mm; pétalas 5,2-6 × 5-6 mm; anteras 4-5 mm compr., gineceu 5-carpelar, ginóforo 0,5 mm compr.; estilete 4-5 mm compr. Mericarpos 7-10 × 4-5 mm, obcônicos, ápice arredondado; carpóforos 6-15 × 3-6 mm.

Material examinado: Borda, 22.X.2005, fl. e fr., J.S. Silva Filha 43 (UFP); Fragmento chave, 18.XII.2009, fr., E. Pessoa 234 (UFP); Mata da Cruzinha, 30.X.2008, fl., fl., A.C.B. Lins 362 (UFP); Mata de BR, 19.XII.2008, fr., P.G.A. Mendes 55 (UFP); Mata de Zambana, 8.IV.2008, fl. e fr., M.A.M. Silva 95 (UFP).

Ocorre em todos os domínios fitogeográficos do Brasil e na Região Nordeste há registros nos estados da Bahia, Maranhão e Piauí (Chacon \& Yamamoto 2011), sendo esta a primeira citação para o estado de Pernambuco. Relacionada à $O$. hexasperma porém diferencia-se pelas sépalas persitentes no fruto imaturo e 5 carpelos (Sastre 1988). Usada na ornamentação, construção civil, carpintaria e como medicinal (Pio Corrêa 1984).

3. Ouratea crassa Tiegh. Ann. Soc. Nat., Bot. ser. 8, 16:262. 1902.

Árvores 6-7 m alt. Estípulas 8-13 mm compr., deltóides. Folhas 23-35 × 7,3-11 cm, elípticas, coriáceas, ápice agudo, base cuneada a obtusa, margem ondulada, serreada; pecíolo $0,8-1,5 \mathrm{~cm}$, canaliculado. Inflorescência ca. $30 \mathrm{~cm}$ compr.; botões florais 5-7 × 2,5-4 mm, cônicos, ápice agudo, base truncada; pedicelo 7-20 mm compr.; sépalas 9-11 × 3-4 mm; pétalas $11-13 \times 6-7 \mathrm{~mm}$; anteras 7-8 mm compr.; gineceu 5-carpelar, ginóforo 1-1,4 mm compr.; estilete 5-7 mm compr. Mericarpos $5 \times 4 \mathrm{~mm}$, obcônicos, ápice arredondado; cálice persistente; carpóforo 4-5 × 6-8 mm.

Material examinado: Mata da Piedade, 17.XII.2009, fr., J.A.N. Sousa 592 (UFP); Mata de Pezinho, 11.I.2008, fl., A. Alves-Araujo 826 (UFP).

Endêmica da Floresta Atlântica e citada para os estados da Bahia e Sergipe (Chacon \& Yamamoto 2011), sendo aqui o primeiro registro para o estado de Pernambuco. Afim de $O$. castaneifolia, ambas apresentando sépalas persitentes no fruto e gineceu com cinco carpelos, diferindo entre si basicamente pelo tamanho das folhas, inflorescência e flores. 

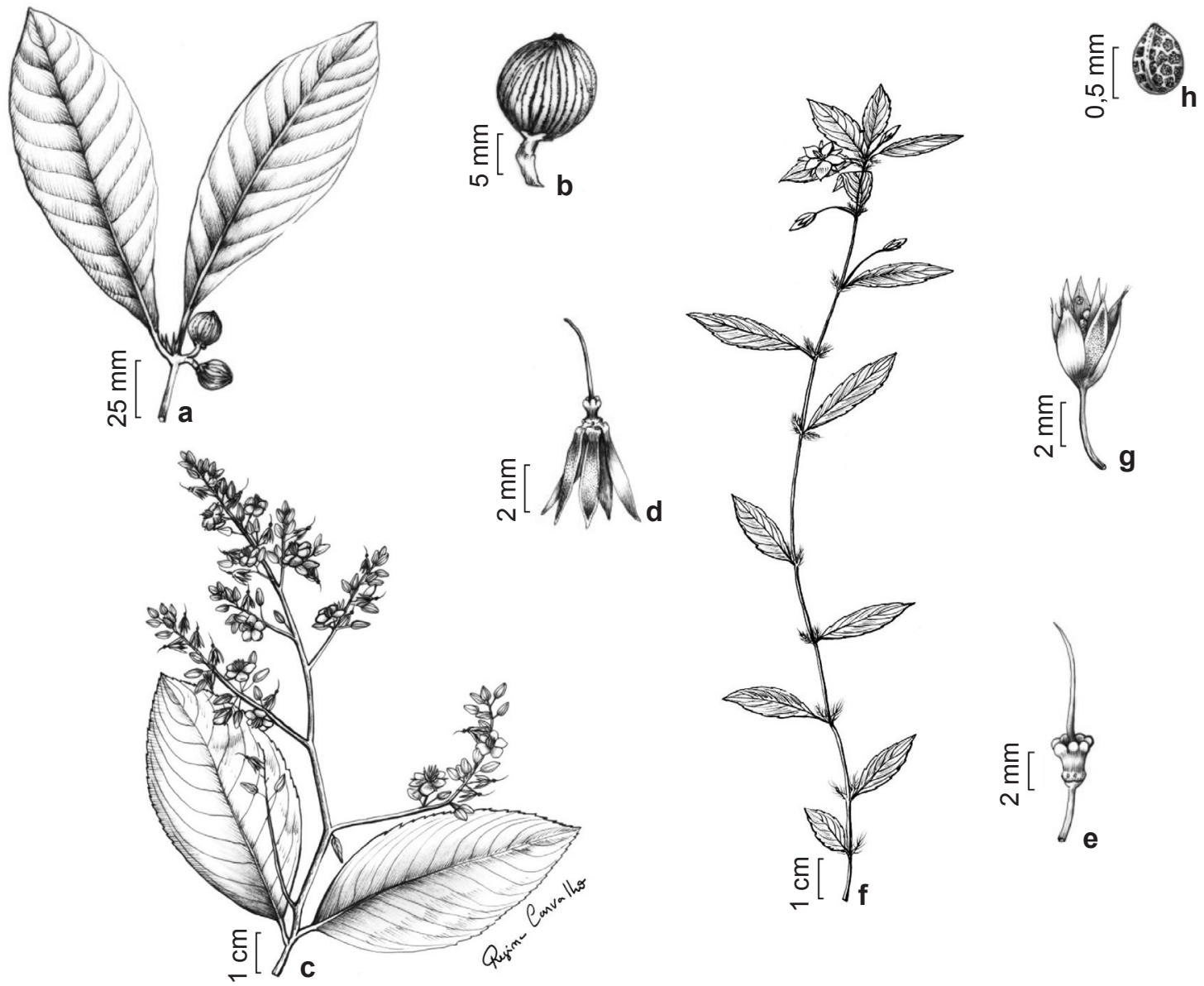

Figura 1 -a-b. Quiina florida - a. detalhe do ramo com estípulas interpeciolares e frutos; b. detalhe do fruto baga estriada longitudinal (Sousa 590). c-d. Ouratea castaneifolia - c. ramo com flores e frutos imaturos com cálice persistente; d. detalhe do fruto imaturo com cálice persistente (Silva 95). e. Ouratea hexasperma - detalhe do fruto imaturo sem cálice (A. Alves-Araujo 840). f-h. Sauvagesia erecta -f. hábito; g. fruto cápsula com sementes; h. semente (A. Alves-Araujo 618). Figure 1 - a-b. Quiina florida - a. details interpeciolares branch with stipules and fruits; b. details berry fruit striated lengthwise (Sousa 590). c-d. Ouratea castaneifolia - c. branch with flowers and immature fruit with persistent calyx; d. detail of immature fruit with persistent calyx (Silva 95). e. Ouratea hexasperma - detail of immature fruit without calyx (A. Alves-Araujo 840). f-h. Sauvagesia erecta - f. habit; g. fruit capsule with seeds; h. seed (A. Alves-Araujo 618).

4. Ouratea hexasperma (A.St.-Hil.) Baill. Hist. Pl. 4: 366.1873.

Fig. 1e

Arvoretas a árvores, $7-8 \mathrm{~m}$ alt. Estípulas caducas. Folhas 9-10 × 3,5-4 cm, elípticas, cartáceas, ápice acuminado, base obtusa, margem ondulada, levemente serrilhada; pecíolo $0,4-0,5$ cm. Inflorescência 16-19 cm compr.; botões florais 6×3-4 mm, ovalados, cônicos, ápice agudo, base arredondada, pedicelo 5-12 $\mathrm{mm}$ compr.; sépalas 6,5-7 × 2-4 mm; pétalas 6-8 × 6-8 $\mathrm{mm}$; anteras 5-6 mm compr., gineceu 6-7-carpelar, ginóforo 0,8-1 mm compr.; estilete 5-7 $\mathrm{mm}$ compr. Mericarpos 4-7 × 5-6 mm compr., obcônicos, ápice arredondado; cálice caduco; carpóforo 4-9 $\times 6-8 \mathrm{~mm}$.

Material examinado: Mata de Zambana, 14.II.2008, fl. e fr., A. Alves-Araujo 840 (UFP, IPA).

Material Adicional: BRASIL. PARAÍBA: Mamanguape, Reserva Biológica Guaribas, Área II, Trilha Caiana, 18.III.2010, fr., F. O. Silva 90 (JPB); 27.IX.2009, fl. e fr., F. O. Silva 18 (JPB).

Amplamente distribuída no Brasil (Chacon \& Yamamoto 2011), ocorrendo na USJ na borda dos fragmentos. A espécie é comum em áreas de tabuleiro, cerrado típico e em ambientes antropizados (Chacon et al. 2003). Diferencia-se das demais espécies de Ouratea ocorrentes na USJ pelas sépalas 
caducas no fruto imaturo e pelo gineceu 6-8 carpelar e (O. castaneifolia e $O$. crassa apresentaram sépalas persistentes no fruto imaturo e gineceu 5 carpelar).

\section{Sauvagesia L.}

Ervas eretas. Estípulas aos pares, ciliadas, persistentes. Folhas com margem plana, esparsamente serreada, nervação camptódroma, nervuras secundárias divergindo mais ou menos retilíneas da principal. Flores isoladas ou bóstrices, axilares. Pétalas espatuladas, alvas, róseas ou lilases; estaminódios livres, os externos numerosos, ápice reniforme internos 5 , petalóides; estames 5 , anteras subsésseis, lisas, gineceu 3 carpelar, ginóforo ausente, estilete terminal. Cápsula septicida trivalvar, lisa; sementes numerosas.

Predominantemente neotropical (Amaral 1991) e com cerca de 40 espécies (Sastre 1997), 31 das quais ocorrem no Brasil (Cardoso 2011) e centro de diversidade nos estados de Minas Gerais e Bahia (Zappi \& Lucas 2002).

\section{Sauvagesia erecta L., Sp. Pl. 1:203. 1753.}

Fig.1f-h

Erva 0,4-0,6 m alt. Estípulas 4-6 mm compr., ensiformes. Folha 1-3 × 0,4-1 cm, elípticas a elíptico-lanceoladas, membranáceas, ápice agudo, base atenuada à cuneada, margem plana, serreada. Flores isoladas ou bóstrices de 1-3 floros; botões florais 4-6 mm compr., cônicos, ápice agudo, pedicelo 6-12 mm compr.; sépalas 5-6 × 1-2 $\mathrm{mm}$, lanceoladas a ovalado-lanceolada; pétalas 5-6 × 3-3,5 mm.; estaminódios externos 0,5-1 mm compr.; internos 5,2-3 x $1 \mathrm{~mm}$; filetes $0,1-0,3 \mathrm{~mm}$ compr., anteras $2 \mathrm{~mm}$ compr.; carpelo subprotundo; estilete 2,5-3 mm compr. Cápsula 6-7 mm compr., ovóide. Sementes numerosas.

Material examinado: Mata do Pezinho, 11.I.2008, fl., $A$. Alves-Araujo 820 (UFP); Mata de Zambana, 18.X.2007, fl. e fr., A. Alves-Araujo 618 (UFP, IPA).

Apresenta ampla distribuição em todos os domínios fitogeográficos do Brasil (Cardoso 2011), florescendo e frutificando praticamente o ano todo. $\mathrm{Na}$ USJ ocorre em áreas úmidas e próximas a cursos d'água.

\section{Referências}

Amaral, M.C.E. 1991. Phylogenetische Systematik der Ochnaceae. Botanische Jahrbücher für Systematik 113: 105-196.

Amorim, B. \& Alves. 2011. Flora da Usina São José, Igarassu, Pernambuco: Myrtaceae. Rodriguésia 62: 499-514.
APG - Angiosperm Phylogeny Group II. 2003. An update of the angiosperm phylogeny group classification for the orders and families of flowering plants: APG II. Botanical Journal of the Linneun Society 141: 399-436.

APG - Angiosperm Phylogeny Group III. 2009. An update of the angiosperm phylogeny group classification for the orders and families of flowering plants: APG III. Botanical Journal of the Linneun Society 161: 105-121.

Alves-Araújo, A. \& Alves, M. 2010. Flora da Usina São José, Igarassu, Pernambuco: Sapotaceae. Rodriguésia 61: 303-318.

Buril, M.T. \& Alves, M. 2011. Flora da Usina São José, Igarassu, Pernambuco: Convolvulaceae. Rodriguésia 62: 093-105.

Cardoso, D.B.O.S. 2011. Sauvagesia. In: Forzza, R.C. et al. (eds.). Lista de espécies da flora do Brasil. Jardim Botânico do Rio de Janeiro. Disponível em $<$ http://floradobrasil.jbrj.gov.br/2011/FB019940>. Acesso em 23 Set 2011.

Chacon, R.G. \& Yamamoto, K. 2011. Ouratea. In: Forzza, R.C. et al. (eds.). Lista de espécies da flora do Brasil. Jardim Botânico do Rio de Janeiro. Disponível em <http://floradobrasil.jbrj.gov. br/2011/FB115385>. Acesso em 23 Set 2011.

Chacon, R.G.; Yamamoto, K.; Cardoso, D.B.O.S.; Feres, F. \& Fraga, C.N. 2011. Ochnaceae. In: Forzza, R.C. et al. (eds.). Lista de espécies da flora do Brasil. Jardim Botânico do Rio de Janeiro. Disponível em $<$ http://floradobrasil.jbrj.gov.br/2011/FB000174>. Acesso em 23 Set 2011.

Chase M.W.; Fay M. F. \& Savolainen V. 2000. Higherlevel classification in the angiosperms: new insights from the perspective of DNA sequence data. Taxon 49: 685-704.

Melo, A.; Alves-Araujo, A. \& Alves, M. 2010. Burmanniaceae e Gentianaceae da Usina São José, Igarassu, Pernambuco. Rodriguesia 60: 431-440.

Pio Corrêa, M. 1984. Dicionário das plantas úteis do Brasil. vol. III. Ministério da Agricultura, Instituto Brasileiro de Desenvolvimento Florestal. 646p.

Pontes, T.A.; Andrade, I.M. \& Alves, M. 2010. Flora da Usina São José: Araceae. Rodriguésia 1: 689-704.

Rocha, A.E.S. \& Alves-Araujo, A. 2011. Quiinaceae. In: Forzza, R.C. et al. (eds.). Lista de espécies da flora do Brasil. Jardim Botânico do Rio de Janeiro. Disponível em $<$ http://floradobrasil.jbrj. gov.br/2011/FB000202>. Acesso em 23 Set 2011.

Sastre, C. 1988. Studies on the Flora of the Guianas 34. Synopsis generis Ouratea Aublet (Ochnaceae). Bulletin du Muséum National d'Histoire Naturelle, Paris 4e. sér., 10, section B, Adansonia 1: 47-67.

Sastre, C. 1997. Uma espécie nova de Sauvagesia L. (Ochnaceae) do campo rupestre do estado de Goiás. Boletim de botânica da Universidade de São Paulo 16: 71-73. 
Sastre, C. 2003a. Ochnaceae. In: Steyermark J.A.; Berry, P.E.; Yatskievych, K. \& Holst, B.K. (eds.). Flora of the Venezuelan Guayana. Vol. 7. Missouri Botanical Garden Press, Saint Louis. Pp. 124-16.

Sastre, C. 2003b. Ochnaceae. In: Smith, N. (ed.). Flowering plants of the neotropics. Princeton University Press, Princeton. Pp. 274-275.

Sastre, C. 2003c. Ochnaceae. In: Mori, S.A. et al. (eds.). Guide to the vascular plants of the Central French Guiana. Vol. 76, part 2. The New York Botanical Garden Press, New York. Pp. 554-558.

Schneider, J.V.; Swenson, U. \& Zizka G. 2002. Phylogenetic reconstruction of the neotropical family Quiinaceae (Malpighiales) based on morphology with remarks on the evolution of an androdioecious sex distribution. Annals of the Missouri Botanical Garden 89: 64-76.

Schneider, J.V.; Swenson, U.; Samuel, R.; Stuessy, T. \& Zizka, G. 2006. Phylogenetics of Quiinaceae (Malpighiales): evidence from trnL-trnF sequence data and morphology. Plant Systematics and Evolution 257: 189-203.

Souza, F.O. \& Bianchini, R.S. 2007. Quiinaceae. In: Wanderley, M.G.L.; Shepherd, G.J.; Melhem, T.S.A. \& Giulietti, A.M. (eds.). Flora fanerogâmica do estado de São Paulo. Vol. 5. Ed. Instituto de Botânica, São Paulo. Pp. 255-258.

Souza, V.C. \& Lorenzi, H. 2008. Botânica sistemática: Guia ilustrado para identificação das famílias de fanerógamas nativas e exóticas no Brasil, baseado em APG II. $2^{\mathrm{a}}$ ed. Instituto Plantarum, Nova Odessa. 704p.

Savolainen, V.; Fay, M.F.; Albach, D.C.; Backlund, A.; van der Bank, M.; Cameron, K.M.; Johnson, S.A.; Lledo, M.D.; Pintaud, J.C.; Powell, M.; Sheahan, M.C.; Soltis, D.E.; Soltis, P.S.; Weston, P.; Whitten, W.M.; Wurdack, K.J. \& Chase, M.W. 2000. Phylogeny of the eudicots: a nearly complete familial analysis based on rbcL gene sequences. Kew Bulletin 55: 257-309.

Thiers, B. 2011 [continuously updated]. Index Herbariorum: a global directory of public herbaria and associated staff. New York Botanical Garden's Virtual Herbarium. Disponível em $<$ http://sweetgum. nybg.org/ih/>. Acesso em 15 Ago 2011.

Trindade, M.B.; Lins-e-Silva, A.C.B.; Silva, H.P.; Figueira, S.B. \& Schess1, M. 2008. Fragmentation of the Atlantic rainforest in the northern coastal region of Pernambuco, Brazil: Recent changes and implications for conservation. Bioremediation, Biodiversity and Bioavailability 2: 5-13.

Zappi, D.C. \& E. Lucas. 2002. Sauvagesia nitida Zappi \& Lucas (Ochnaceae) - a new species from Catolés, Bahia, NE Brazil, and notes on Sauvagesia in Bahia \& Minas Gerais. Kew Bulletin 57: 711-717.

Zizka, G. \& Schneider, J.V. 2004. Quiinaceae. In: Smith N.P.; Mori S.A.; Henderson A.; Stevenson D.W. \& Heald S.V. (eds.). Flowering plants of the neotropics. Princeton University Press, Princeton. Pp. 317-318. 